\title{
Effects of Dichloroacetate in the Treatment of Hypoxic Lactic Acidosis in Dogs
}

\author{
Helmut Graf, William Leach, and Allen I. Arieff \\ Nephrology Research, Veterans Administration Medical Center; and University of California, San Francisco, California 94121
}

\begin{abstract}
The metabolic and systemic effects of dichloroacetate (DCA) in the treatment of hypoxic lactic acidosis were evaluated in the dog and compared with the infusion of equal quantities of volume and sodium. Hypoxic lactic acidosis was induced by ventilating dogs with an hypoxic gas mixture of $8 \%$ oxygen and $92 \%$ nitrogen, resulting in arterial $\mathrm{PO}_{2}$ of $<30 \mathrm{mmHg}$, pH below 7.20, bicarbonate $<15 \mathrm{mM}$, and lactate $>7 \mathrm{mM}$. After, the development of hypoxic lactic acidosis dogs were treated for $60 \mathrm{~min}$ with either DCA as sodium salt or $\mathbf{N a C l}$ at equal infusions of volume and sodium.
\end{abstract}

Dogs treated with DCA showed a significant increase of arterial blood pH and bicarbonate, and steady levels of lactate, whereas $\mathrm{NaCl}$ resulted in further declines of blood $\mathrm{pH}$ and bicarbonate, and rising blood lactate levels. Overall lactate production decreased during therapy with either regimen, but hepatic lactate extraction increased significantly with DCA, while it remained unchanged with $\mathrm{NaCl}$. Tissue lactate levels in liver and skeletal muscle decreased significantly with DCA treatment but were unchanged with $\mathrm{NaCl}$. Additionally, an increase in muscle intracellular pH was observed only in DCA treated dogs. A possible mechanism for the observed actions of DCA might be related to a significant increase in oxygen delivery to tissues. Such an effect was found with DCA administration, but was not observed with $\mathrm{NaCl}$ therapy.

In conclusion, DCA therapy in hypoxic lactic acidosis has beneficial systemic effects compared with therapy with $\mathrm{NaCl}$. DCA administration is accompanied by increases of blood pH and bicarbonate, a decrease in lactate production, and enhanced liver lactate extraction, and a lowering of tissue lactate levels.

\section{Introduction}

Hypoxic lactic acidosis is a clinical entity that includes those clinical conditions characterized by lactate accumulation associated with direct evidence for tissue hypoxia (1). It is a common clinical situation with a mortality rate of $>80 \%$ when blood lactate levels exceed $5 \mathrm{mM}(1,2)$. The mainstay of therapy for hypoxic lactic acidosis has usually been the administration of $\mathrm{NaHCO}_{3}$ in order to compensate for the low blood bicarbonate values generally observed in metabolic acidosis (3). Recent data from our laboratory, however, have demonstrated that administration of $\mathrm{NaHCO}_{3}$ in hypoxic lactic acidosis is associated with detrimental systemic effects as well as with several untowards metabolic actions, thus warranting the search for alternative treatment modalities $(4,5)$.

Dr. Graf is on leave from the 2nd Department of Internal Medicine, University of Vienna, Austria. Address correspondence to Dr. Arieff, VA Medical Center.

Received for publication 10 January 1985.

The Journal of Clinical Investigation, Inc.

Volume 76, September 1985, 919-923
Dichloroacetate (DCA) ${ }^{1}$ is a substance that lowers blood lactate levels in a variety of experimental and clinical situations (6). Little research has been done on the effects of DCA in hypoxic lactic acidosis, and some of the available results are conflicting. Earlier studies suggested that DCA is not able to prevent lactate production from hypoxic tissues (7). Subsequently, however, it was found that the recovery phase from hypoxic lactic acidosis was markedly accelerated after pretreatment with DCA (8). More recent data have shown that DCA effectively lowers blood lactate levels in some patients who had lactic acidosis due to tissue hypoxia (9). Additionally, preliminary evidence of a lactate-lowering effect of DCA has been presented in a rat model of hypoxic lactic acidosis (10).

The present experiments evaluated the effects of DCA in a dog model of hypoxic lactic acidosis (11). As we have previously shown that $\mathrm{NaHCO}_{3}$ has adverse systemic and metabolic effects in the treatment of hypoxic lactic acidosis, we decided to compare the effects of DCA in the treatment of hypoxic lactic acidosis with treatment with $\mathrm{NaCl}$ delivering the same volume and quantity of sodium, thus enabling us to look for effects not attributable to volume expansion.

\section{Methods}

Studies were carried out in two groups of mongrel dogs of both sexes, mean weight $20.2 \pm 2.9 \mathrm{~kg}$, fasted for $16 \mathrm{~h}$. The groups were: dogs with hypoxic lactic acidosis who were treated with $1 \mathrm{M} \mathrm{NaCl}$ at a rate of 2.5 $\mathrm{meq} / \mathrm{kg}$ per $\mathrm{min}$ for $60 \mathrm{~min}(n=7)$; dogs with hypoxic lactic acidosis who were treated with sodium dichloroacetate. The DCA was infused at a rate of $300 \mathrm{mg} / \mathrm{kg}$ per $\mathrm{h}$ for $60 \mathrm{~min}$, again delivering a sodium infusion rate of $2.5 \mathrm{meq} / \mathrm{kg}$ per $\mathrm{h}(n=7)$.

The animals were anesthetized with pentobarbital, intubated, and mechanically ventilated (12). Arterial $\mathrm{PCO}_{2}$ was adjusted to $\sim 35 \mathrm{mmHg}$ by small adjustments of the tidal volume. The abdomen was opened via a midline abdominal incision and teflon cannulas were placed in the aorta (Ao) via the femoral artery (FA), in the hepatic portal vein (HPV) via a branch of the splanchnic vein, and in the hepatic vein (HV) via the jugular vein. Blood flow to liver, extrahepatic splanchnic tissues (gut) and skeletal muscle (carcass) was measured by flow measurements in the appropriate vessels as previously described (12-14). Cardiac output was measured by the thermodilution technique and mean aortic blood pressure was monitored via a catheter through the FA (13).

Hypoxic lactic acidosis was produced by ventilating the dogs with an hypoxic gas mixture of $8 \%$ oxygen and $92 \%$ nitrogen (11). By varying the amount of oxygen, the arterial $\mathrm{PO}_{2}$ was adjusted to a level where blood bicarbonate steadily declined to a level of $\sim 12 \mathrm{mM}$, which has been found to correspond to an arterial lactate of $\sim 7 \mathrm{mM}$ after $90 \mathrm{~min}$ of hypoxia.

In both groups, measurements were made of lactate, bicarbonate, $\mathrm{pH}, \mathrm{PCO}_{2}$ and $\mathrm{PO}_{2}$ in arterial and femoral venous (FV) blood as previously described (12). Similar measurements were obtained in blood from hepatic and hepatic portal veins. Muscle samples from the vastus lateralis and samples of liver tissue from different lobules were obtained and

1. Abbreviations used in this paper: Ao, aorta; DCA, dichloroacetate; FA, femoral artery; FV, femoral vein; HPV, hepatic portal vein, HV, hepatic vein; $\mathrm{pHi}$, intracellular $\mathrm{pH}$. 
processed to allow measurement of intracellular $\mathrm{pH}(\mathrm{pHi})$ and tissue lactate levels as previously described $(12,13)$.

Oxygen delivery was determined in the following manner. $\mathrm{The}^{\mathrm{PO}_{2}}$ was measured in Ao and HPV. Oxygen content of blood was then determined from the measurement of hematocrit, the respective $\mathrm{PO}_{2}$, and constants for the blood oxygen dissociation curve and whole blood $\mathrm{O}_{2}$ capacity in dogs, with correction for the Bohr effect (15). Total oxygen delivery to tissues was calculated by multiplying oxygen content of aortic blood with the corresponding cardiac index value. Based on flow measurements in HPV and hepatic artery, the amount of oxygen delivered to the liver was calculated by taking a weighted mean of hepatic portal venous and aortic oxygen content $(0.75 \times \mathrm{HPV}+0.25 \times \mathrm{Ao})$ and multiplying it times the total liver blood flow (HPV + hepatic artery [HA]), as previously described (14). Delivery of oxygen to extrahepatic splanchnic tissues was calculated by multiplying oxygen content of arterial blood times the HPV flow, and oxygen delivery to skeletal muscle (carcass) by multiplying arterial oxygen content times carcass flow. Fractional hepatic lactate uptake was calculated as lactate extracted by the liver divided by lactate load presented to the liver (14). The extrahepatic splanchnic lactate production (gut) (micromolar per kilogram per hour) was calculated by multiplying the lactate concentration difference from Ao to HPV by the HPV blood flow. Carcass lactate production (micromolar per kilogram per hour), representing predominantly the lactate production from skeletal muscle, was calculated by multiplying the difference in lactate concentrations between Ao and FV times the carcass blood flow. In the control state, carcass blood flow represents a constant fraction (44.3\%) of cardiac output (16). Femoral artery flow (FA) was monitored, and carcass blood flow was assumed to vary in proportion to changes in FA flow.

Data are presented as mean \pm SE. For statistical analysis, the $t$ test for paired data was used for comparisons within the groups; for comparisons between the two groups, the $t$ test for unpaired data was used.

\section{Results}

Blood acid base values (Figs. 1 and 2). At the beginning of the treatment with either $\mathrm{NaCl}$ or DCA, dogs in both groups showed comparable degrees of hypoxic lactic acidosis. Treatment with DCA resulted in a significant increase of blood $\mathrm{pH}(P<0.01)$, whereas $\mathrm{NaCl}$-treated animals showed a further decrease of blood $\mathrm{pH}(P<0.05)$. Thus, after $60 \mathrm{~min}$ of treatment, arterial $\mathrm{pH}$ was significantly greater in DCA-treated animals $(P<0.001)$. Concomitantly, blood bicarbonate increased significantly with DCA $(P<0.001)$ and decreased further with $\mathrm{NaCl}(P<0.05)$, again

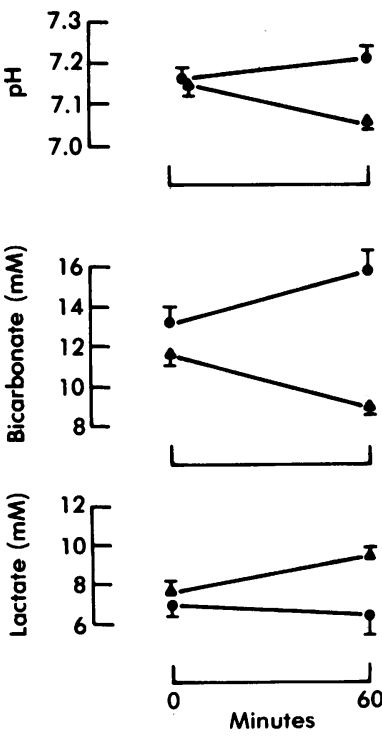

Figure 1. Effects of treatment with DCA and $\mathrm{NaCl}$ on acid-base values in dogs with hypoxic lactic acidosis. For significance levels, see text. Values are mean $\pm \mathrm{SE} ; \boldsymbol{n}=7$ in each group. $\bullet, \mathrm{DCA} ; \Delta, \mathrm{NaCl}$.

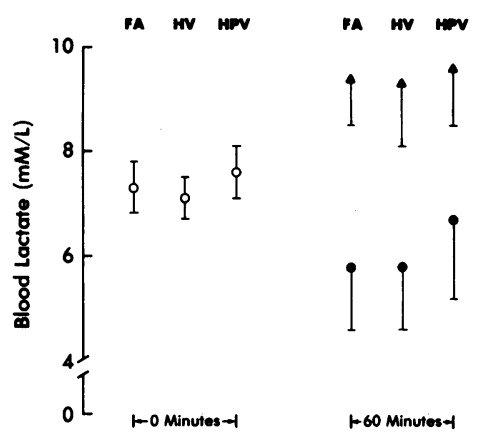

Figure 2. Comparative effects of $60 \mathrm{~min}$ of therapy with DCA (๑) or $\mathrm{NaCl}(\Delta)$ on blood lactate levels in FA, HV, and HPV of dogs with hypoxic lactic acidosis. Values are mean $\pm \mathrm{SE} ; n=7$ in each group.

resulting in a significant difference between the two groups after 60 min of therapy $(P<0.001)$. Blood lactate values in the FA as well as in HV and HPV did not increase further with DCA, but did continue to rise during $\mathrm{NaCl}$ infusion $(P<0.05)$. As a result, after $60 \mathrm{~min}$ of treatment, blood bicarbonate was greater $(P<0.01)$ in DCA-treated dogs. In both groups, arterial $\mathrm{PCO}_{2}$ was not altered during treatment (from $35 \pm 2$ to $35 \pm 2 \mathrm{mmHg}$ in group a, and from $38 \pm 1$ to $41 \pm 2 \mathrm{mmHg}$ in group b), and arterial $\mathrm{PO}_{2}$ values were comparable at the beginning $(27 \pm 3$ $\mathrm{mmHg}$ in group a, and $25 \pm 1 \mathrm{mmHg}$ in group b), and were unchanged during the $60 \mathrm{~min}$ of either therapy $(28 \pm 3 \mathrm{mmHg}$ in group $a$, and $25 \pm 1 \mathrm{mmHg}$ in group $b$, respectively). Treatment with both DCA and $\mathrm{NaCl}$ resulted in similar increases of serum sodium (from $134 \pm 2 \mathrm{meq} / \mathrm{liter}$ to $144 \pm 3 \mathrm{meq} / \mathrm{liter}$ with DCA vs. $135 \pm 4 \mathrm{meq} /$ liter to $145 \pm 3 \mathrm{meq} / \mathrm{liter}$ with $\mathrm{NaCl}$ ), whereas serum potassium was unchanged with both treatment regimens (from $3.8 \pm 0.2 \mathrm{meq} / \mathrm{liter}$ to $3.9 \pm 0.4 \mathrm{meq} / \mathrm{liter}$ with DCA vs. $4.0 \pm 0.3 \mathrm{meq} /$ liter with $\mathrm{NaCl})$.

Hemodynamic values (Fig. 3). During treatment with either DCA or $\mathrm{NaCl}$, no significant changes in mean arterial blood pressure occurred, and the values at 15-min intervals were not significantly different in DCA- vs. NaCl-treated animals. Parallel to this, the cardiac index was not significantly altered during
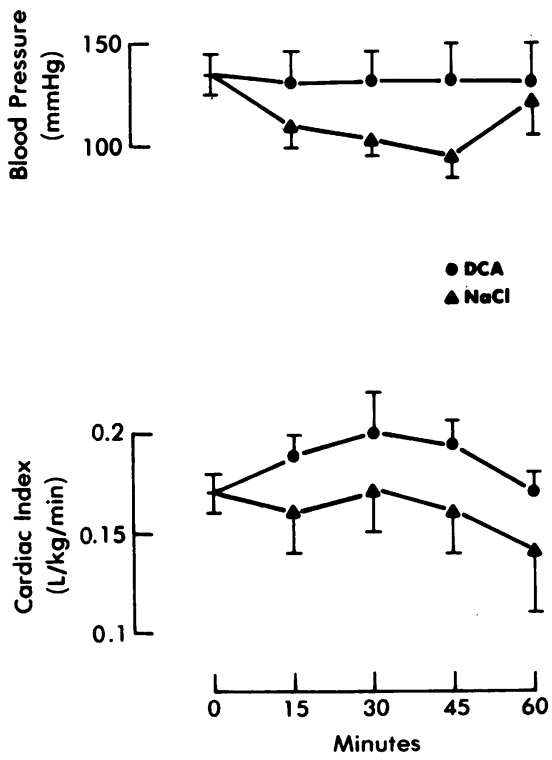

Figure 3. Hemodynamic values in dogs with hypoxic lactic acidosis treated with DCA or $\mathrm{NaCl}$. The differences between the two groups are not significant. Values are mean $\pm \mathrm{SE} ; n=7$ in each group. 
Table I. Overall Oxygen Delivery and Oxygen Delivery to Liver, Extrahepatic Splanchnic Tissues (Gut) and Skeletal Muscle (Carcass) in Dogs with Hypoxic Lactic Acidosis Treated with NaCl or DCA

\begin{tabular}{|c|c|c|c|c|c|c|c|c|}
\hline & \multicolumn{4}{|l|}{$\mathrm{NaCl}$} & \multicolumn{4}{|l|}{ DCA } \\
\hline & Overall & Liver & Gut & Carcass & Overall & Liver & Gut & Carcass \\
\hline & $\mathrm{ml} \mathrm{O}_{2} / \mathrm{kg} / \mathrm{min}$ & $\mathrm{ml} \mathrm{O}_{2} / \mathrm{kg} / \mathrm{min}$ & $\mathrm{ml} \mathrm{O}_{2} / \mathrm{kg} / \mathrm{min}$ & $\mathrm{mlO}_{2} / \mathrm{kg} / \mathrm{min}$ & $\mathrm{ml} \mathrm{O}_{2} / \mathrm{kg} / \mathrm{min}$ & $\mathrm{ml} \mathrm{O}_{2} / \mathrm{kg} / \mathrm{min}$ & $\mathrm{ml} \mathrm{O}_{2} / \mathrm{kg} / \mathrm{min}$ & $\mathrm{ml} \mathrm{O}_{2} / \mathrm{kg} / \mathrm{min}$ \\
\hline $0 \mathrm{Min}$ & $9.26 \pm 1.91$ & $0.40 \pm 0.08$ & $0.98 \pm 0.20$ & $4.08 \pm 0.84$ & $8.04 \pm 0.85$ & $0.43 \pm 0.05$ & $1.04 \pm 0.11$ & $3.54 \pm 0.37$ \\
\hline $60 \mathrm{Min}$ & $7.45 \pm 1.40$ & $0.39 \pm 0.08$ & $0.96 \pm 0.18$ & $3.30 \pm 0.62$ & $9.77 \pm 0.94^{*}$ & $0.58 \pm 0.05^{*}$ & $1.50 \pm 0.14^{*}$ & $4.31 \pm 0.41^{*}$ \\
\hline
\end{tabular}

Values are mean \pm SE. $n=7$ in each group. ${ }^{*}$ Denotes $P<0.01$ vs. the paired value at 0 min.

therapy with either DCA or $\mathrm{NaCl}$, with no significant difference between the two groups after 60 min of therapy. The mean blood flows at the beginning of treatment were $20 \pm 2 \mathrm{ml} / \mathrm{kg}$ per min for gut, and $25 \pm 2 \mathrm{ml} / \mathrm{kg}$ per min for liver, respectively. After treatment with DCA, the gut blood flow had increased to $26 \pm 2$ $\mathrm{ml} / \mathrm{kg}$ per $\mathrm{min}$, while that in liver was $32 \pm 2 \mathrm{ml} / \mathrm{kg}$ per min, although the changes were not statistically significant. Smaller changes that were not significant also occurred with $\mathrm{NaCl}$ treatment, where gut blood flow was found to be $18 \pm 3 \mathrm{ml} / \mathrm{kg}$ per min and liver blood flow $22 \pm 4 \mathrm{ml} / \mathrm{kg}$ per min after $60 \mathrm{~min}$.

Oxygen delivery (Table I). Overall oxygen delivery as well as oxygen delivery to the individual organ systems was severely depressed at the beginning of the individual treatment protocols (Table I). Whereas oxygen delivery to all tissues remained unchanged throughout the $60 \mathrm{~min}$ of $\mathrm{NaCl}$ therapy, there was a significant rise in both overall and individual organ oxygen delivery in the DCA-treated dogs (Table I).

Lactate production and extraction (Figs. 4 and 5). After 90 min of hypoxia, arterial lactate was $7.5 \mathrm{mM}$ in dogs weighing $20.2 \mathrm{~kg}$. If one assumes a volume of distribution for lactate of $50 \%$ of total body water, then $91 \mathrm{mM}$ of lactate in excess of that metabolized was produced in $90 \mathrm{~min}$, or $1 \mathrm{mM} / \mathrm{min}$. The lactate production from gut and carcass was $3,000 \mu \mathrm{M} / \mathrm{kg}$ per $\mathrm{h}$, or 1 $\mathrm{mM} / \mathrm{min}$. Thus, virtually all the lactate produced in hypoxic lactic acidosis was produced by the gut and carcass. After therapy with DCA, lactate production from gut and carcass fell from 3,300 to $2,008 \mu \mathrm{M} / \mathrm{kg}$ per $\mathrm{h}$, while with $\mathrm{NaCl}$, lactate production declined from 3,091 to $1,913 \mu \mathrm{M} / \mathrm{kg}$ per h. As shown in Fig. 4, with $\mathrm{NaCl}$ therapy, there was a significant decrement of gut, but
GUT

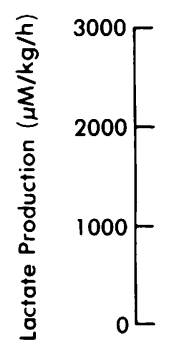

CARCASS

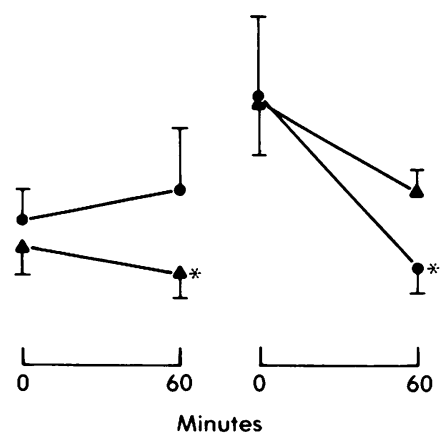

Figure 4. Influence of treatment with DCA (•) or $\mathrm{NaCl}(\Delta)$ on lactate production by gut and carcass in dogs with hypoxic lactic acidosis. For significant levels, see text. Values are mean $\pm \mathrm{SE} ; n=7$ in each group. not carcass, lactate production $(P<0.05)$. Gut lactate production after $60 \mathrm{~min}$, however, was not significantly different from that found in DCA-treated animals. With DCA, carcass but not gut lactate production fell significantly $(P<0.003)$. The net result was that there was no significant difference between DCA- and $\mathrm{NaCl}$-treated animals in terms of net lactate production after $60 \mathrm{~min}$ of therapy. Liver lactate extraction, expressed as the percentage of the load delivered to the liver, increased significantly with DCA $(P<0.01)$, and was unchanged with $\mathrm{NaCl}$ treatment.

Tissue pHi and tissue lactate values (Fig. 6). Liver pHi showed a small but not significant increase with both DCA and $\mathrm{NaCl}$ therapy. Parallel to this there was a significant decrease of liver tissue lactate levels with DCA treatment $(P<0.001)$, which was not observed with $\mathrm{NaCl}$. However, muscle $\mathrm{pHi}$ increased significantly with DCA $(P<0.01)$, but not with $\mathrm{NaCl}$ therapy. In parallel, muscle tissue lactate levels decreased significantly in DCA-treated animals $(P<0.003)$, as did muscle lactate production (Fig. 4).

\section{Discussion}

These data show that in dogs with hypoxic lactic acidosis, therapy with DCA has important and potentially beneficial metabolic and hemodynamic effects. DCA therapy is associated with an increase of both blood $\mathrm{pH}$ and bicarbonate as well as a lower blood lactate level than in treatment with $\mathrm{NaCl}$ (Figs. 1 and 2). This is due to both a decrease in carcass lactate production and an increase in hepatic lactate extraction. There is also a lowering of liver tissue lactate levels, and a significant decrease of muscle tissue lactate levels, which probably leads to the observed increase in muscle pHi (Fig. 4). The high cardiac output state associated with hypoxic lactic acidosis is maintained by DCA, and the blood pressure is unaltered. Thus tissue perfusion, a key factor in tissue hypoxia, is not compromised. A possible mechanism of action of DCA in hypoxic lactic acidosis may well be related to the significant increase in oxygen delivery to all tissues evaluated (gut, skeletal muscle, liver, Table I).

Continuously rising blood lactate values accompanied by further decreases in blood $\mathrm{pH}$ and bicarbonate as observed in $\mathrm{NaCl}$-treated animals (Fig. 1) are the consequence of both impaired lactate utilization by the liver and the presence of overproduction of lactate by extrahepatic splanchnic tissues and skeletal muscle (5). This rise occurs despite a significant decrease in gut lactate production in NaCl-treated animals (Fig. 4), but can be largely explained by the greatly reduced capacity of the liver to extract lactate (Fig. 5) when compared with normal values. Earlier studies from our laboratory have shown that there 


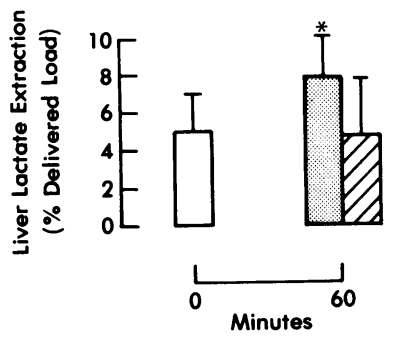

Figure 5. Liver lactate extraction during treatment with DCA ( $(\mathrm{\theta})$ or $\mathrm{NaCl}($ (⿴囗十) in dogs with hypoxic lactic acidosis. For significance levels, see text. Values are mean $\pm \mathrm{SE} ; \boldsymbol{n}$ $=7$ in each group.

is a continuous rise of blood lactate levels similar to that observed in $\mathrm{NaCl}$-treated animals, when both gut and carcass lactate production and hepatic lactate extraction are unchanged (5). It would appear that amelioration of some of the metabolic alterations found in hypoxic lactic acidosis would occur with a decrease of lactate production accompanied by a significant increase in hepatic lactate extraction. Treatment with DCA significantly lowers carcass lactate production (Fig. 4) and concomittantly increases hepatic lactate extraction (Fig. 5). The net result of these two effects is to avoid a further increase in blood lactate levels, although there is not a net decrease. This can be largely explained by the greatly diminished ability of the liver to extract lactate. Although there is almost a doubling of the absolute amount of lactate removed, this still falls far short of its capacity. We have previously shown that under normoxic conditions the liver is capable of increasing the lactate extraction rate in response to an intravenous lactate load to $\sim 16 \%$ of the filtered load (11), a value which very closely resembles its maximum capacity evaluated at the recovery from hypoxic lactic acidosis by reoxygenation.

The lactate-lowering properties of DCA are attributed to a stimulatory action on the pyruvate dehydrogenase enzyme complex $(17,18)$. It has been shown in the perfused rat heart that under ischemic conditions the pyruvate dehydrogenase complex is significantly decreased, resulting in an increased lactate release (19). As pyruvate dehydrogenase is most abundant in muscle tissue (20), DCA in hypoxic lactic acidosis can exert its major effect on muscle lactate production. In contrast to its effect on muscle, DCA apparently does not influence lactate release from the gut (Fig. 4). Similar findings have been obtained in the diabetic $\operatorname{dog}(20)$ and in dogs with phenformin lactic acidosis (14), and it has been suggested that the pyruvate dehydrogenase complex in gut may be fundamentally different from skeletal muscle (21).

The hemodynamic alterations found in hypoxic lactic acidosis have been shown to consist of a high cardiac output, a decreased peripheral resistance, and normal arterial blood pressure $(5,11)$. This is probably a compensatory response to sustain tissue oxygenation in the presence of decreased oxygen delivery to tissues because of the hypoxemia. In contrast to therapy with $\mathrm{NaHCO}_{3}$, which results in significant decreases of blood pressure and cardiac output (4), treatment with either DCA or $\mathrm{NaCl}$ does not alter this state. In the treatment of hypoxic lactic acidosis, a further decrease in tissue perfusion, which would necessarily follow a decrease of cardiac output, would only add a hypoxic stimulus to the tissue. As has been shown with $\mathrm{NaHCO}_{3}$ therapy of hypoxic lactic acidosis, this consequently results in further increases of blood lactate levels (4). Additionally, the effect of DCA on tissue oxygen delivery is significantly greater than that observed with $\mathrm{NaCl}$ (Table I). In DCA-treated animals, there is a $20 \%$ increase in overall oxygen delivery, which results in sig- nificant increases of $\mathrm{O}_{2}$ delivery to liver, extrahepatic splanchnic tissues, and skeletal muscle, whereas oxygen delivery in $\mathrm{NaCl}$ treated animals is not significantly altered (Table I). The increase in oxygen delivery to tissue by DCA can probably best be explained by a combination of several different events, all of which can affect the binding of oxygen to hemoglobin. Such events would include alterations in blood $\mathrm{pH}$ and $\mathrm{PCO}_{2}$, as well as changes in red cell 2,3-DPG levels (22-24). DCA might affect any of these, but in our study, we found only an increase of blood pH (Fig. 1). Changes in 2,3-DPG are unlikely to occur in as short an interval as covered by this experiment, and changes in $\mathrm{PCO}_{2}$ did not occur. Some other as yet undescribed effect of DCA might also have contributed.

The significant increase of hepatic lactate extraction in dogs treated with DCA could be explained at least in part by the significant decrease of liver tissue lactate levels, which is not observed with administration of $\mathrm{NaCl}$ (Fig. 6). This decrease of liver tissue lactates may precede significant changes of liver $\mathrm{pHi}$ that did not occur during these $60 \mathrm{~min}$ of treatment. On the other hand, direct effects of DCA on the liver unrelated to activation of the pyruvate dehydrogenase, such as amino acid transamination, production of oxalate and glyoxalate, and stimulation of fatty acid synthesis, might also have contributed (6).

The significant decrease of carcass production seen in DCAtreated animals (Fig. 4) results in a significant decrease of muscle tissue lactate levels and is associated with a significant increase of muscle $\mathrm{pHi}$. Neither effect was observed in $\mathrm{NaCl}$-treated animals (Fig. 6).

Chronic administration of DCA may be associated with certain toxic effects such as neurotoxicity, cataracts, and mutagenicity (6). However, more recent evidence suggests that mutagenetic effects of DCA may have been related to impurities in the preparation, and that such effects are not observed when crystalline DCA is used (25). In short-term administration in humans, no serious side effects of DCA have been noted (9).

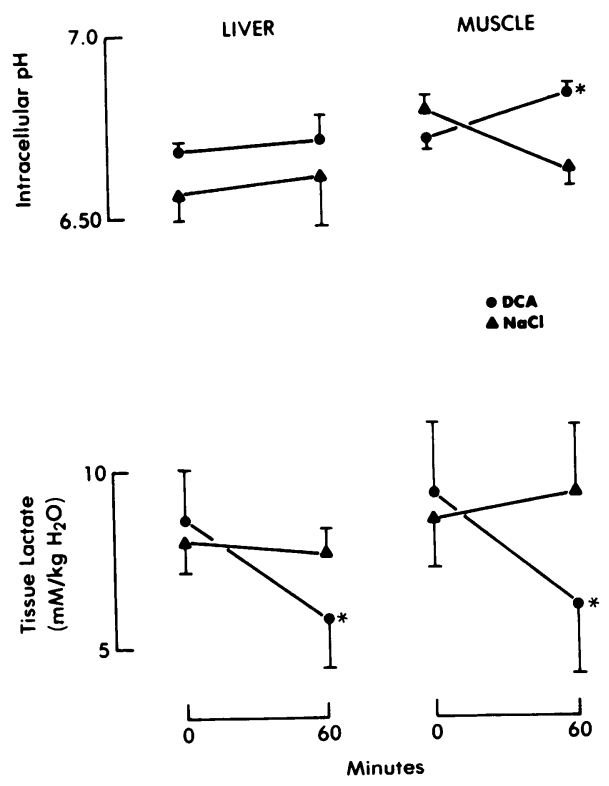

Figure 6. Influence of treatment with $\mathrm{DCA}$ or $\mathrm{NaCl}$ on intracellular $\mathrm{pH}$ of liver and muscle, and on tissue lactate levels in liver and muscle. For significance levels, see text. Values are mean \pm SE; $n=7$ in each group. 
Extrapolation of our data, which was obtained in experimental animals with a uniform circulatory behavior, to the clinical situation must be done with caution. Patients with hypoxic lactic acidosis may present with either low, normal, or high cardiac output and blood pressure. Such variables may influence the response to therapy. However, taking into account the high mortality rate of hypoxic lactic acidosis and the persistently high mortality associated with the traditional therapy with $\mathrm{NaHCO}_{3}$, the results of our study, which shows that DCA is able to reverse many of the major pathological manifestations of hypoxic lactic acidosis, seem to warrant further human studies.

\section{Acknowledgments}

This work was supported by grant AM 18350 from the National Institute of Arthritis, Diabetes, Digestive \& Kidney Diseases of the Department of Health \& Human Services, and by the Research Service of the VA Medical Center. Dr. Graf is supported by a grant from the Max Kade Foundation.

\section{References}

1. Cohen, R. D., and H. F. Woods. 1976. Type A lactic acidosis. In Clinical and Biochemical Aspects of Lactic Acidosis. R. D. Cohen and H. F. Woods, editors. Blackwell Scientific Publications, Oxford. 77-91.

2. Broder, G., and M. H. Weil. 1964. Excess lactate: an index of reversibility of shock in human patients. Science (Wash. DC). 143:14571459.

3. Narins, R. G., E. R. Jones, R. Townsend, D. A. Goodkin, and R. J. Shay. 1985. Metabolic acid base disorders: pathophysiology, classification, and treatment. In Fluid, Electrolyte and Acid-Base Disorders. A. I. Arieff and R. A. DeFronzo, editors. Churchill-Livingstone, New York and London. 269-384.

4. Graf, H., W. Leach, and A. I. Arieff. 1985. Evidence for a detrimental effect of bicarbonate therapy in hypoxic lactic acidosis. Science (Wash. DC). 227:754-756.

5. Graf, H., W. Leach, and A. I. Arieff. 1985. Metabolic effects of $\mathrm{NaHCO}_{3}$ in hypoxic lactic acidosis in dogs. Am. J. Physiol. In press.

6. Crabb, D. W., E. A. Yount, and R. A. Harris. 1981. The metabolic effects of dichloroacetate. Metab. Clin. Exp. 30:1024-1039.

7. Loubatieres, A. L., G. Ribes, and G. Valette. 1976. Pharmacological agents and acute experimental hyperlactataemia in the dog. Br. J. Pharmacol. 58:429P.

8. Loubatieres, A., G. Valette, G. Ribes, M. M. Loubatieres-Mariani, and A. M. Rondot. 1978. Dichloroacetate de sodium: son application a la therapeutique des hyperlactatemies experimentales. Diabete Metab. 4:5-11.
9. Stacpoole, P. W., E. M. Harman, S. H. Curry, T. G. Baumgartner, and R. I. Misbin. 1983. Treatment of lactic acidosis with dichloroacetate. N. Engl. J. Med. 309:390-396.

10. Scheid, J., S. Abu Romeh, and R. L. Tannen. 1985. Effect of Na-dichloroacetate in hypoxic lactic acidosis in rats. Kidney Int. 27:152. (Abstr.)

11. Arieff, A. I., R. Park, and W. Leach. 1982. Pathogenesis of hypoxic lactic acidosis in dogs. Kidney Int. 21:143a. (Abstr.)

12. Arieff, A. I., R. Park, W. Leach, and V. C. Lazarowitz. 1980. Pathophysiology of experimental lactic acidosis in dogs. Am. J. Physiol. 239:F135-F142.

13. Park, R., W. J. Leach, and A. I. Arieff. 1979. Determination of liver intracellular $\mathrm{pH}$ in vivo and its homeostasis in acute acidosis and alkalosis. Am. J. Physiol. 236:F240-F245.

14. Park, R., A. I. Arieff, W. Leach, and V. C. Lazarowitz. 1982. Treatment of lactic acidosis with dichloroacetate in dogs. J. Clin. Invest. 70:853-862.

15. Altman, P. L., and D. S. Dittmer. 1974. Blood oxygen dissociation curves: mammals. In Biology Data Book, Vol. III. P. L. Altman and D. S. Dittmer, editors. Federation of American Societies for Experimental Biology, Bethesda. Second ed. 1863-1871.

16. Smith, C. R., and R. L. Hamlin. 1977. Regulation of the heart and blood vessels. In Dukes' Physiology of Domestic Animals. M. J. Swenson, editor. Cornell University Press, Ithaca, NY. Ninth ed. 102120.

17. Whitehouse, S., and P. J. Randle. 1973. Activation of pyruvate dehydrogenase in perfused rat heart by dichloroacetate. Biochem. J. 134: 651-653.

18. Whitehouse, S., R. H. Cooper, and P. J. Randle. 1974. Mechanism of activation of pyruvate dehydrogenase by dichloroacetate and other halogenated carboxylic acids. Biochem. J. 141:761-774.

19. Patel, T. B., and M. S. Olson. 1984. Regulation of pyruvate dehydrogenase complex in ischemic rat heart. Am. J. Physiol. 246:H858H864.

20. Park, R., P. R. Radosaevich, W. J. Leach, P. Seto, and A. I. Arieff. 1983. Metabolic effects of dichloroacetate in diabetic dogs. Am. J. Physiol. 245:E94-E101.

21. Diamond, M. P., R. C. Rollings, L. Erlendson, P. E. Williams, W. W. Lacy, D. Rabin, and A. D. Cherrington. 1980. Dichloroacetate: its in vivo effects on carbohydrate metabolism in the conscious dog. Diabetes. 29:702-709.

22. Bellingham, A. J., J. C. Detter, and C. Lenfant. 1971. Regulatory mechanisms of hemoglobin oxygen affinity in acidosis and alkalosis. $J$. Clin. Invest. 50:700-706.

23. Kilmartin, J. V. 1976. Interaction of haemoglobin with protons, $\mathrm{CO}_{2}$ and 2,3-Diphosphoglycerate. Br. Med. Bull. 32:209-212.

24. Tyuma, I. 1984. The Bohr effect and the Haldane effect in human hemoglobin. Japanese J. Physiol. 34:205-216.

25. Waskell, L. 1978. A study of the mutagenicity of anesthetics and their metabolites. Mutat. Res. 57:141-153. 